\title{
The uncertain role of unmodified mesenchymal stem cells in tumor progression: what master switch?
}

\author{
Liyang Zhang, Juanjuan Xiang* and Guiyuan Li*
}

\begin{abstract}
Mesenchymal stem cells (MSCs) are emerging as promising gene vectors for cancer therapy because of their unique characteristics, including the ease of their expansion and genetic modification and their remarkable tumor-tropic properties. However, there remains a concern that MSCs may promote cancer progression. Surprisingly, there are conflicting reports within the literature describing both the promotion and inhibition of cancer progression by MSCs. The reasons for this discrepancy are still unknown. The surface markers, differentiation ability, and tumorigenic roles of MSCs, as well as their effect on immunoregulation, produce heterogeneity. In this review, we describe the heterogeneity of MSCs by the species from which they are derived, the methodology for their isolation and the context of their interactions with cancer cells. The conflicting roles of MSCs in tumor progression may be attributable to the bimodal effect of unmodified MSCs on immunoregulation. MSCS have been reported to suppress T-cell function and inhibit graft-versus-host disease (GVHD). On the other hand, MSCs elicit the graft-versus-tumor (GVT) effect in some cases. Selective allodepletion may be used to dissociate GVHD from the GVT effect. Understanding the conditions that balance GVHD and the GVT effect of MSCs may be crucial to advance cancer therapy research with respect to MSCs.
\end{abstract}

Cancer is a highly prevalent, life-threatening disease that affects people around the world. The major limitation of cancer therapeutic strategies is the lack of tumor

*Correspondence: xiangjj@csu.edu.cn; ligy@xysm.net

Cancer Research Institute, Key Laboratory of Carcinogenesis and Cancer Invasion of Ministry of Education, Key Laboratory of Carcinogenesis of Ministry of Health, Central South University, 110 Xiangya Road, Changsha, Hunan, 410078, PR China specificity [1]. Pre-clinical and clinical studies have shown that stem cell-based therapies hold tremendous promise for the treatment of human disease [2]. Mesenchymal stem cells (MSCs) have been considered as potential therapeutic cells for tissue repair, bone fracture, cartilage defects, graft-versus-host disease (GVHD), inflammatory disorders and type I diabetes [3-5]. The potency of MSCs for differentiation is the basic premise on which regenerative medicine is established. MSCs have the ability to differentiate into osteocytes and chondrocytes. Because of their multipotency, MSCs have also been used for treating heart failure and for neural repair [6,7]. In addition to their ability to differentiate into damaged tissues, MSCs secrete cytokines and chemokines that provide the beneficial effects of regenerative medicine [8].

Recently, the extension of the therapeutic potential of MSCs to cancer therapy has raised great interest. For cancer gene therapy, it is important to achieve the expression of the therapeutic gene at specific tumor sites. Gene vectors are vehicles that deliver and express the corrective genes to specific sites. To date, gene vectors can mainly be divided into two categories: viral and nonviral. Although there has been intensive research focus on developing cancer cell-targeting viral and non-viral vectors, the benefits are still modest. MSCs have inherent tumor-tropic migratory properties, which allow them to serve as vehicles for delivering effective, targeted therapy to primary tumors and metastatic sites [2]. Despite their tremendous potential, the effects of MSCs as therapeutic agents in cancers still need to be explored. Expression of exogenous anticancer molecules in MSCs by retroviruses or lentiviruses raises concerns regarding the potential risks associated with insertional mutation. In addition, it remains controversial whether unmodified MSCs promote tumorigenesis.

\section{Bimodal nature of MSCs in tumorigenesis}

Conflicting reports within the literature have indicated that MSCs act to either promote or inhibit cancer progression. The reason for this discrepancy is still 
unknown. It is important to elucidate the effects of MSCs on tumor progression before they are considered for use in clinical trials for cancer therapy.

There is substantial evidence supporting an inhibitory role of MSCs on cancer progression. MSCs are thought to inhibit tumor growth by increasing inflammatory infiltration [9], inhibiting angiogenesis [10], and suppressing Wnt signaling [11,12] and AKT signaling [13], which have been reviewed in detail elsewhere [14]. Human MSCs have been shown to inhibit the proliferation of tumor cells and induce apoptosis in tumor cells in vitro via soluble factors [15]. Agents derived from extracts of umbilical cord MSCs have been reported to have tumor-inhibitory properties [16]. Additionally, human skin-derived MSCs significantly inhibit glioblastoma growth in two different tumor models by releasing high amounts of transforming growth factor- $\beta$ and down-regulating vascular endothelial growth factor, which might contribute to decreased tumor cell invasion and the number of tumor vessels [17]. Bone marrowderived MSCs can be safely expanded in vitro and are not susceptible to malignant transformation, suggesting these cells are suitable for cancer cell therapy [18].

On the other hand, the role of MSCs in promoting cancer progression is also supported by several studies. There is evidence suggesting that some cancers may originate from normal stem cells [19]. Although genomic stability of MSCs in long-term cell cultures has been described, concerns regarding the possibility that MSCs undergo malignant transformation have still been raised. Spontaneous malignant transformation of MSCs in vitro was reported in adipose tissue and bone marrow-derived MSCs [20-22]; however, one of these that reported malignantly transformed MSCs was later confirmed to be cross-contaminated with human fibrosarcoma or osteosarcoma cell lines during the primary culture [9]. Murine MSCs have been shown to be less stable and more prone to malignant transformation than their human counterparts [23]. MSCs have been described to localize to tumor sites, where they integrate into the tumorassociated stroma [24,25]. MSCs interact with tumor cells to promote tumor growth directly or indirectly in an autocrine or paracrine manner. Cancer cell-derived cytokines induce secretion of soluble factors by MSCs. The resulting factors operate in an autocrine manner to induce expression of a group of cytokines by the MSCs, then proceed to act in a paracrine fashion on the cancer cells [26]. These cancer-promoting effects are mostly dependent on inflammatory cytokines secreted by MSCs [24]. MSCs could be involved in cell survival, invasion, and motility through cytokine signaling $[24,27,28]$. MSCs are efficient in the chemoattraction of endothelial cells and promote angiogenesis [29] and are also able to differentiate into endothelial cells and vessel pericytes, thus contributing to neovasculogenesis [30-32]. The immunosuppressive properties of MSCs can also partly explain their cancer-promoting functions. A discrepancy also exists between in vitro and in vivo behavior, suggesting the involvement of the tumor microenvironment [33].

Some research has attributed the discrepancy of the effects of MSCs on tumorigenesis to the timing of MSC introduction into tumors [14]. In vivo studies were performed injecting mixed MSCs and cancer cells or MSCs alone into animal models with established tumors. The presence of MSCs during early tumor growth may facilitate angiogenesis [14]. The injection timing actually reflects the ratio of MSCs and cancer cells. In many coinjection studies, MSCs are usually injected at an equal number with their cancer counterparts, whereas when injected into the established tumor animal model, much fewer MSCs reach the tumor site compared to the cancer cells. When MSCs are the primary component of the tumor microenvironment, they have a tendency to promote metastasis $[24,27,34]$. The minimized direct contact of MSCs during tumor initiation may have a tendency to inhibit tumor cell growth [14]. This finding strongly indicates that the interaction between MSCs and tumor cells is important to fully understand the impact of MSCs on tumor progression. MSCs along with other bone marrow-derived cells migrate to the sites of the primary tumor and prime distant tissues for tumor cell implantation and proliferation $[24,35,36]$. MSCs that are recruited to the tumor stroma create a cancer stem cell niche via cytokine networks [26,37]. They interact with cancer cells and tumor-resident neighbors such as fibroblasts and macrophages. They also provide the homing sites for metastatic cells, leading to the establishment of metastatic foci. The primary tumorderived vascular endothelial growth factor, placental growth factor (PlGF) or recently recognized exosomes induce reprogrammed bone marrow progenitors toward a pro-vasculogenic phenotype and support tumor growth and metastasis $[36,38,39]$. The multipotent differentiation of MSCs may be the decisive factor affecting cancer behavior. In addition to having the potential to differentiate into osteocytes, chondrocytes and adipocytes, MSCs have been described to have the potential to differentiate into neurocytes, heart cells and tumorassociated fibroblasts (TAFs). TAFs are part of the tumor stroma and provide functional and structural support for tumor progression and development. In addition to promoting angiogenesis and the proliferative capacity of tumor cells, TAFs have been implicated in enhancing tumor cell invasiveness, possibly through the induction of epithelial-mesenchymal transition [40]. There are several suggested origins for TAFs, including tissueresident cells, circulating cells and epithelial-mesenchymal-transformed cells [25]. It is postulated that TAFs 
are derived from a subset of 'specialized' MSCs due to the high degree of similitude between the two cell types $[25,41]$. It was reported that under long-term tumorigenic conditions in vitro, MSCs expressed TAF-like proteins [25]. MSCs are supposed to lack hematopoietic cell markers such as CD34 and CD45; however, under tumorigenic conditions, CD11b, CD34 and CD45 were also expressed in MSCs [42,43]. When co-implanted with metastatic cancer cells, all bone marrow-derived MSCs persisted and integrated into tumor stroma, but only CD11b-positive subsets of MSCs significantly promoted tumor growth and metastasis [42]. Under tumorigenic conditions, MSCs underwent hematopoietic differentiation and showed characteristics of macrophage cells [43]. Considering the close relationship between macrophages and tumor cells, the roles of MSCs in tumor progression become more elusive. The hematopoietic differentiation potential of MSCs makes cancer and the tumor microenvironment more complex.

\section{Phenotypically and functionally heterogeneous MSCs}

MSCs are highly heterogeneous and differ in their surface marker composition, shape and capacity for proliferation and differentiation [44]. It is possible that only a subset of MSCs within a population possesses multipotent differentiation potential and promotes tumorigenesis, while another subset inhibits tumorigenesis. The expansion of a primitive subset of these cells was not established until the development of fluorescence-activated cell sorting (FACS) and magnetic-activated cell sorting (MACS). Different cell markers may be used to determine cell differentiation potency (Figure 1). The expression of CD71, CD73 and CD105 does not seem to be important for chondrogenic differentiation in adipose tissue-derived MSCs [45]; however, MSCs derived from synovial membranes, especially the CD105(+) subpopulation, have a superior chondrogenic capacity [46]. CD73 was found to be expressed exclusively during osteogenesis but not adipogenesis in murine MSCs [47]. CD133 is considered to be a marker of neural hematopoietic stem cells; however, CD133-positive MSCs can also be isolated from mobilized peripheral blood, umbilical cord blood and bone marrow. This cell fraction is considered to have high proliferative potential [48]. CD133-positive cells from human bone marrow were demonstrated to have a wide range of differentiation potential, encompassing not only mesodermal but also ectodermal (neurogenic) cell lineages [49]. Less than 30\% of MSCs contributed to cardiomyocyte differentiation. MSCs that differentiate into cardiomyocytes expressed the early cardiac markers GATA4 and NKX2.5 but not cTnT, alpha-actin, CD44 and CD90 and had no potential for adiopogenesis, osteogenesis or chondrogenesis after induction [50]. Increased tumor-homing properties were found in a specific MSC subpopulation that exhibited an enhanced multipotent capacity and increased cell surface expression of specific integrins (integrins alpha2, alpha3 and alpha5) [51].

The isolation methods and sources of MSCs vary in different labs. Bone marrow is the main source of MSCs. In addition, MSCs can be isolated from adipose tissue, human umbilical cord Wharton's jelly, and synovial membranes. Although putative surface markers can be found on MSCs, the specificity of these markers is always under a shadow of doubt. These surface markers can also be found on non-stem cells. In addition, a particular marker may only be expressed on stem cells at a certain stage or under certain conditions [52]. This discrepancy of surface marker expression as well as other heterogeneous properties of MSCs may be attributable to the isolation method and source of MSCs. MSCs isolated from human umbilical cord Wharton's jelly by the collagenase/trypsin method are enriched in expression of C-kit and Oct-4 [53]. MSCs from bone marrow and Hoff's fat pad show a high potential to differentiate into chondrocytes whereas MSCs from subcutaneous fat demonstrate a poor potential for chondrogenesis [54]. Rabbit and sheep MSCs were able to differentiate into chondrocytic lineages much more easily than human MSCs [45]. Traditional culture medium for MSCs includes Dulbecco's modified Eagle's medium (DMEM) or minimum essential medium alpha (MEM- $\alpha$ ) supplemented with fetal bovine serum (FBS). Growth factors such as basic fibroblast growth factor (bFGF) are sometimes added to keep the MSCs undifferentiated. Because of the complexity of FBS, the undefined components in FBS may cause inconsistent results [55]. Some alternative serum free media with recombinant growth factors such as platelet-derived growth factor (PDGF), bFGF and transforming growth factor- $\beta$ were confirmed to retain the phenotype, differentiation and colony-forming unit potential of MSCs [55]. The presence of glucose in the medium affects the differentiation status and senescence of MSCs [56]. Although MSCs have been isolated on the basis of plastic adherence in most studies, some researchers isolated a low-adherent subfraction of MSCs with the CD45(-)CD14(+)CD34(+) phenotype that also express common MSC markers. They confirmed that this subpopulation of MSCs is capable of differentiating into endothelial cells that highly express angiogenic markers and exhibit functional properties of the endothelium [57]. Endometrial MSCs express genes involved in angiogenesis/vasculogenesis and steroid hormone/hypoxia responses [58].

\section{Bimodal effect of unmodified MSCs on immunoregulation}

The bimodal nature of unmodified MSCs is not exclusive to tumorigenesis, for MSCs have bimodal function with 


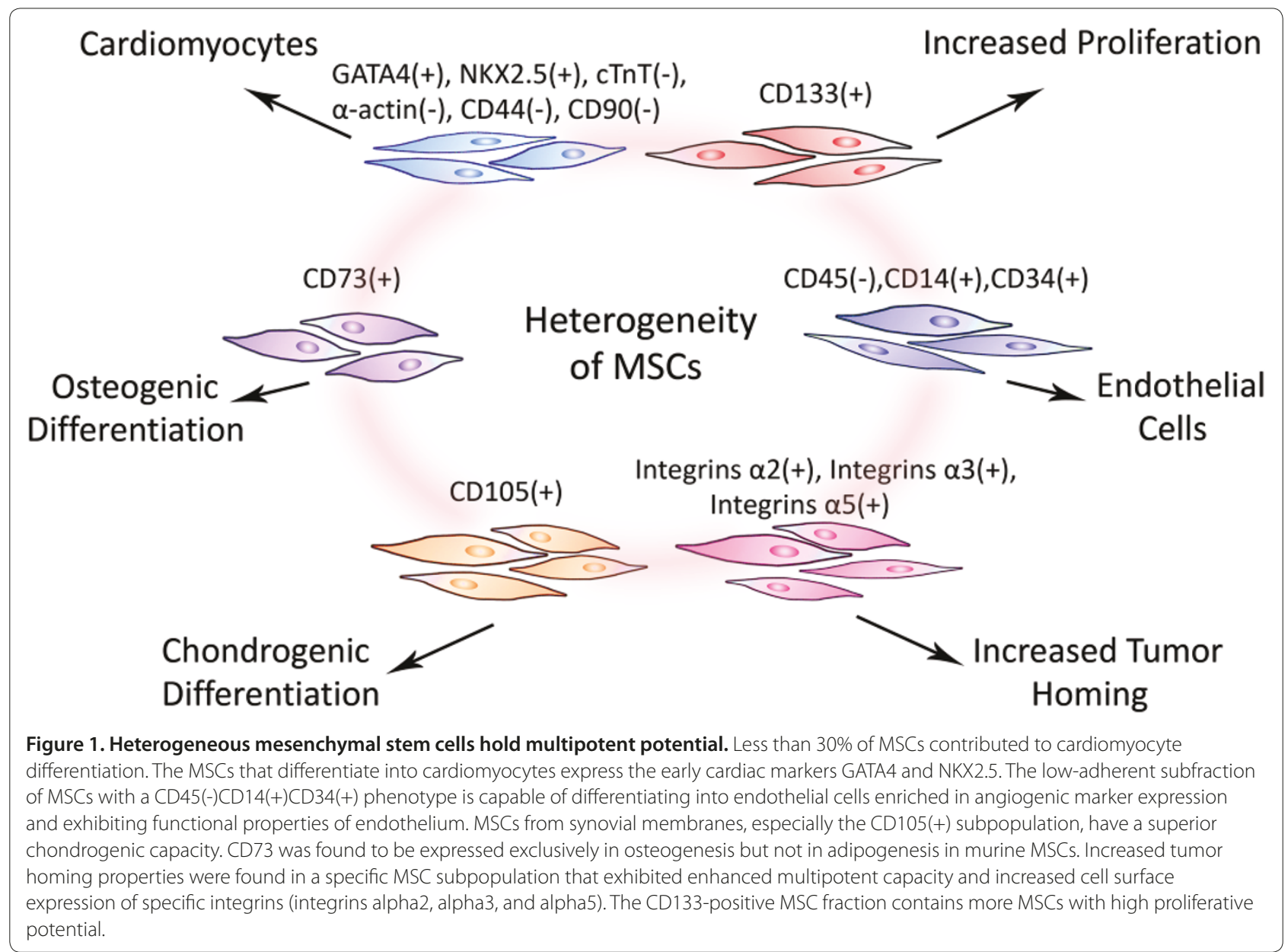

regard to immunoregulation [59]. MSCs are considered to be 'immunologically privileged', as they express a relatively small complement of the molecules that are required for fully activating $\mathrm{T}$ cells [60]. These cells have a reduced expression of both class I and II major histocompatibility complex (MHC) as well as a lack of surface expression of the co-stimulatory molecules CD80, CD86 and CD40 [60]. These properties allow the use of mismatched MSCs in vivo without provoking a proliferative T-cell response [61].

GVHD is a major complication of hematopoietic stem cell transplantation. Co-transplantation of MSCs and hematopoietic stem cells results in fast engraftment and $100 \%$ donor chimerism [4]. Both preclinical and clinical studies have shown that allogeneic transplantation of adipose-derived stem cells is able to control GVHD [62]. Our previous work showed that tumor-bearing mice withstood persistent engraftment of xenogeneic bone marrow-derived MSCs for an extended period of time [63]. Immunosuppression occurs most effectively under conditions in which MSCs make physical contact with an allogeneic tissue and release soluble factors [59].
Adipose-derived stem cells have been shown to lack MHC II expression and its immunosuppressive effects mediated by prostaglandin E2. The suppressive effects of MSCs on immune cells, including T cells, B cells, natural killer (NK) cells and dendritic cells suggest MSCs may be used as a novel therapeutic tool for GVHD and other autoimmune disorders [64]. However, MSCs apparently play multiple roles in immunoregulation in a circumstantial manner. For example, they can act as immune suppressors or stimulators and their expression of $\mathrm{MHC}$ II can either increase or decrease following IFN-gamma stimulation [65]. Additionally, the immunosuppressive property of bone marrow-derived MSCs is altered when they are differentiated [66]. Differentiated MSCs in the tumor microenvironment may show different allogeneic or xenogeneic responses [43]. MSCs from different patients show functional heterogeneity in immunoregulation. The immunosuppressive effect of chronic myelogenous leukemia-derived MSCs on T-cell proliferation is dose dependent [67]. Chronic myelogenous leukemia patient-derived Flk1(+)CD31(-)CD34(-) MSCs have a normal morphology, phenotype and karyotype but 
appear to have an impaired capacity for T lymphocyte inhibition [68]. In comparison to normal MSCs, MSCs from multiple myeloma patients exhibit a normal capacity for differentiation and long-term hematopoietic support but show reduced efficiency in inhibiting T-cell proliferation and produce abnormally high amounts of IL-6 [69]. MSCs from immune thrombocytopenic purpura patients have been shown to have an impaired proliferative capacity and a lower capability of inhibiting activated T-cell proliferation in comparison to cells isolated from healthy donors. Additionally, caspase 9 expression is higher in MSCs from these patients [70].

The tumor microenvironment may influence the immunosuppressive properties of MSCs. The inflammatory factor TNF- $\alpha$ is sufficient to reverse the immunosuppressive effect of MSCs on T-cell proliferation, and this effect was due to an increase in IL-6 secretion [71]. When co-cultured with MSCs at normoxic conditions, the percent of activated HLA-DR(+) T cells is much higher than that observed under hypoxic culture conditions (at 5\% $\mathrm{O}_{2}$ ) [72]. Stro-1-enriched populations elicit a significantly more profound dose-dependent inhibition of lymphocyte proliferation in a mixed lymphocyte reaction than other populations of MSCs [73]. MSCs were also reported to be antigen presenting cells $[65,74]$.

\section{The immunological effect of mesenchymal stem cells may be a critical element in tumorigenesis}

MSCs are a particularly attractive option for cell therapy and tissue engineering applications because they can be used in autologous or allogeneic transplantation, thus avoiding any complications associated with immune rejection. As mentioned above, several studies have demonstrated the suppression of GVHD by MSCs in transplanted recipients [4]. The infusion of donor MSCs to engraftments in the recipient's body may suppress the immune system. Unfortunately, this is the exact property that may promote cancer progression. For cancer therapies, it may be beneficial to elicit the graft-versustumor (GVT) effect. Doctors have found that patients with cancer achieved spontaneous remission following a severe infection. Patients who develop acute or chronic GVHD have lower cancer recurrence rates than patients who did not develop GVHD [75,76].

Although it is rarely reported that MSC transplantation poses a risk of eliciting GVHD, we have found signs that MSCs may elicit GVHD and as well as the GVT effect. In our previous research, Rif-1 fibrosarcoma-bearing syngenic $\mathrm{C} 3 \mathrm{H} / \mathrm{HeN}$ mice were xenotransplanted with ratderived MSCs. Surprisingly, tumors shrank after the xenograft transplantation. The same transplanted mice showed acute liver necrosis (Figure 2). $\mathrm{C} 3 \mathrm{H} / \mathrm{HeN}$ and $\mathrm{C} 3 \mathrm{H} / \mathrm{HeJ}$ mice strains are always used in a wide variety of research areas, including cancer and immunology. $\mathrm{C} 3 \mathrm{H} /$
$\mathrm{HeJ}$ is known to differ from $\mathrm{C} 3 \mathrm{H} / \mathrm{HeN}$ as a result of a mutation at the lps (lipopolysaccharide) locus. Murine mammary tumor virus or leukemia virus caused B-cell activation and increased nuclear factor $\mathrm{\kappa B}$ activation by toll-like receptor 4 in $\mathrm{C} 3 \mathrm{H} / \mathrm{HeN}$ mice but not in $\mathrm{C} 3 \mathrm{H} / \mathrm{Hej}$ mice [77]. $\mathrm{C} 3 \mathrm{H} / \mathrm{HeN}$ is considered to be fully immunocompetent. Therefore, in the experiment described above, we presumed that MSCs may elicit GVHD and the GVT effect. Even in athymic nude mice, the xenogenic transplantation of MSCs resulted in well-differentiated tumor nodules, while acute liver necrosis occurred in the same mice (Figure 2). Acute liver necrosis and skin rash have been identified as indicative of severe GVHD. This finding indicated that the xenotransplantation of MSCs resulted in the GVT effect and GVHD. The following may describe why GVHD and the GVT effect occurred: (1) distinct MSC subsets express MHC I antigens and $\mathrm{T}$ cells cultured with MSCs produce IFN-gamma, indicating alloantigen priming rather than tolerance induction by the MSCs [78]; (2) distinct MSC subsets may differentiate into immune effector cells as described above; (3) the MHC II antigen on MSCs may increase under tumorigenic conditions, presenting antigen to recipient $\mathrm{T}$ cells. The interaction of MSCs and tumor cells increases the complexity of their immunological properties. The generation of soluble factors associated with the immune regulatory properties of MSCs changes when they are co-cultured with cancer cells.

Immunocompromised mice have mostly been used to evaluate the effect of MSCs on tumors, although it is difficult to evaluate the immune response in immunocompromised nude mice. Xenotransplantation differs in a number of important respects from the growth of cancer cells [19]. Mouse growth factors and adhesion molecules sometimes do not bind human receptors [19]. Although cells were transplanted into the immunocompromised mice, even NOD/SCID mice retain an attenuated xenogeneic barrier, not to mention the fact that athymic nu/nu (nude) mice retain high NK cell activation. The xenotransplantation of cancer cells and MSCs may be subject to powerful xenogeneic immune responses in animal models. Tumor-bearing mice are believed to be immunosuppressed to allow the growth of xenogeneic tumors. However, when mice bear a sizable tumor burden, soluble antigenic proteins can elicit a CD4+ $\mathrm{T}$ cell reaction, the development of CD8+ cytotoxic $\mathrm{T}$ lymphocytes and rejection of allogeneic and syngeneic tumors [79]. The immune system of recipients may cause damage to cancer cells as well as certain organs such as liver, gastrointestinal tract or skin. CD8+ cytotoxic $\mathrm{T}$ lymphocytes and NK cells are effector cells displaying cytotoxic activities that can eliminate cancer or infected cells. Nude mice have been considered to exhibit a profound deficiency in T-cell function. However, 


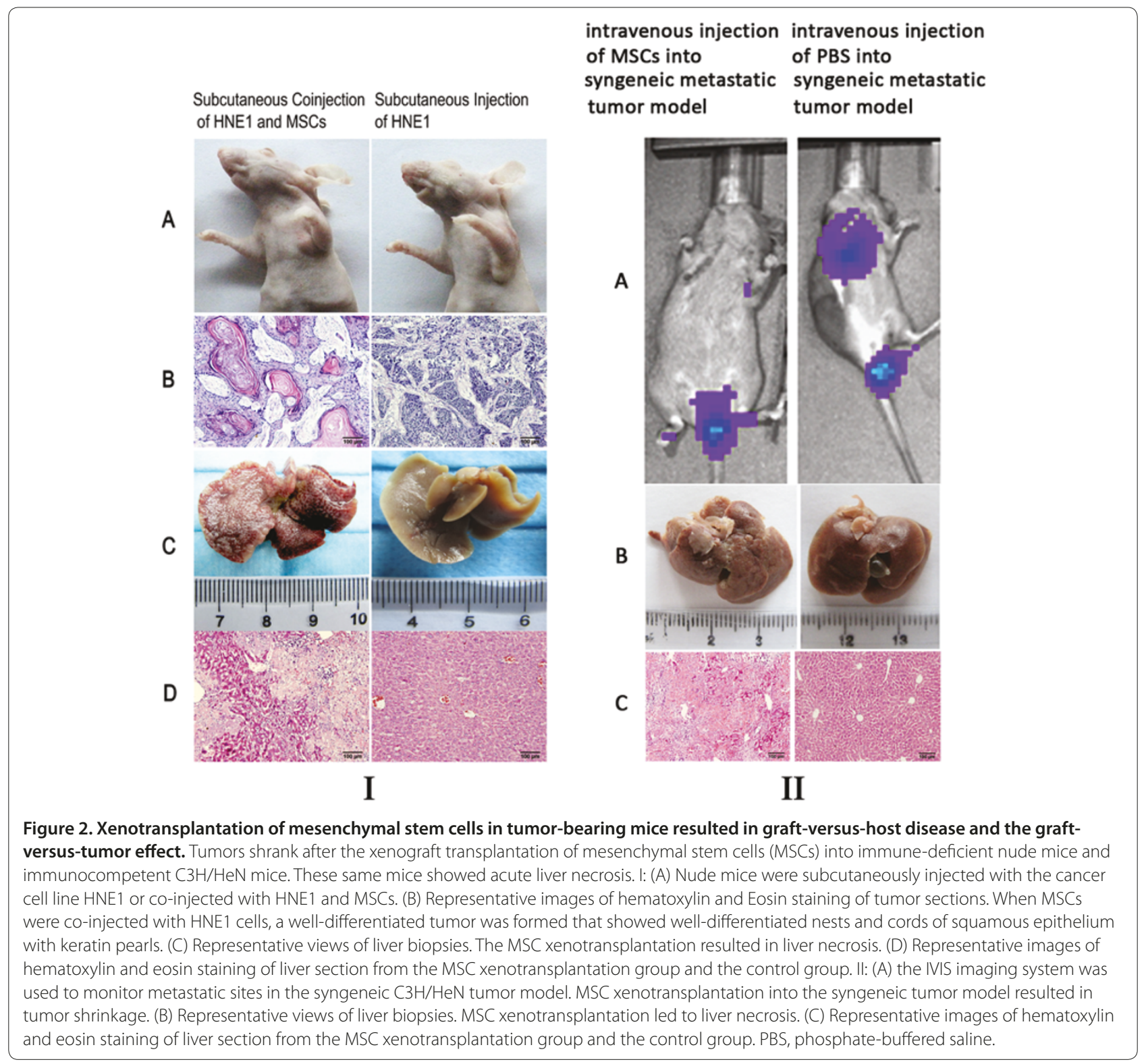

the xenogeneic mixed lymphocyte reaction peaks early when human blood lymphocytes and the spleen cells from nude mice are mixed, indicating the existence of $\mathrm{T}$ like cells in nude mice and thymus-independent proliferation of nude mice B cells in response to human histocompatibility antigens [80]. Gamma-delta T lymphocytes play an important role in the control of cancer, and they have been shown to be implicated in GVHD. Multipotent MSCs effectively suppress the ex vivo expansion of gamma-delta $\mathrm{T}$ cells, although without interfering with their cytotoxic activity [81]. CX3CL1 redirects immune response against tumors in $\mathrm{T}$ - and B-celldeficient Rag1-/- mice but not in NK cell-deficient beige mice and in CX3CR1-/- mice, suggesting a role of
CX3CR1-expressing NK cells in the tumor rejection [82]. Galectin-9 also exerts antitumor activity through T-cellmediated immune responses in nude mice [83]. It has been reported that MSCs can promote the formation of NK cells and enhance their activity against tumor cells at lower doses, while MSCs suppress the formation of NK cells and attenuate their tumor-killing effect at higher doses [84]. Activation of NK cells induced liver injury, accompanied by massive hepatic necrosis and the elevation of transaminases [85]. The systemic inflammatory response induced by this cytokine treatment is critically dependent on NK cells [86]. NKG2D ligand induction might participate in the amplification loop that leads to tissue damage during GVHD. Thus, we presumed that 


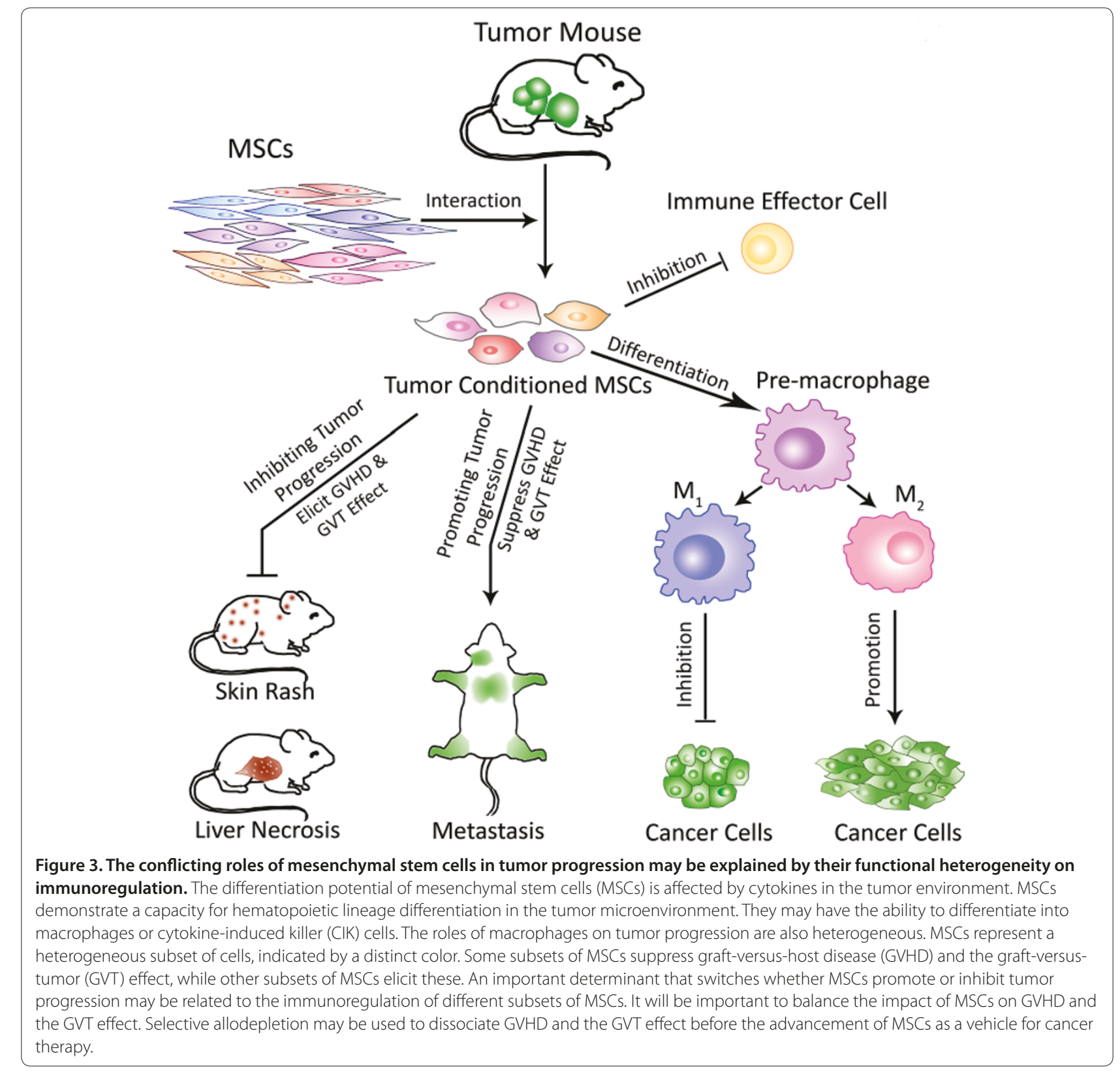

xenotransplantation may activate NK cells and the remaining $\mathrm{T}$-cell function in the nude mouse tumor model mentioned above (Figure 3).

The immunopathology of acute GVHD involves secretion of pro-inflammatory cytokines and subsequent expression of danger signals by the injured host tissue [87]. Just like allogeneic hematopoietic stem cell transplantation, the development of MSCs as cancer gene therapy may be aimed at avoiding lethal GVHD and improving the GVT effect of MSCs. Once the donor's infection-fighting cells are established in the patient's body they may recognize the patient's tissue and cells, including any residual cancer cells, as being different or foreign. In light of their heterogeneity, it is possible that only a subset of MSCs elicits GVHD, while another subset elicits the GVT effect and thus inhibits tumorigenesis. Selective allodepletion has been used to dissociate GVHD from the GVT effect [88] and is a strategy to eliminate host-reactive donor $\mathrm{T}$ cells from hematopoietic stem cell allografts to prevent GVHD [88]. The host dendritic cells, unselected peripheral blood mononuclear cells, can be used as a stimulator population. When cocultured with a stimulator population, host allospecificity may be activated, causing the expression of different surface-specific markers and the population with specific markers can be depleted using negative selection by 


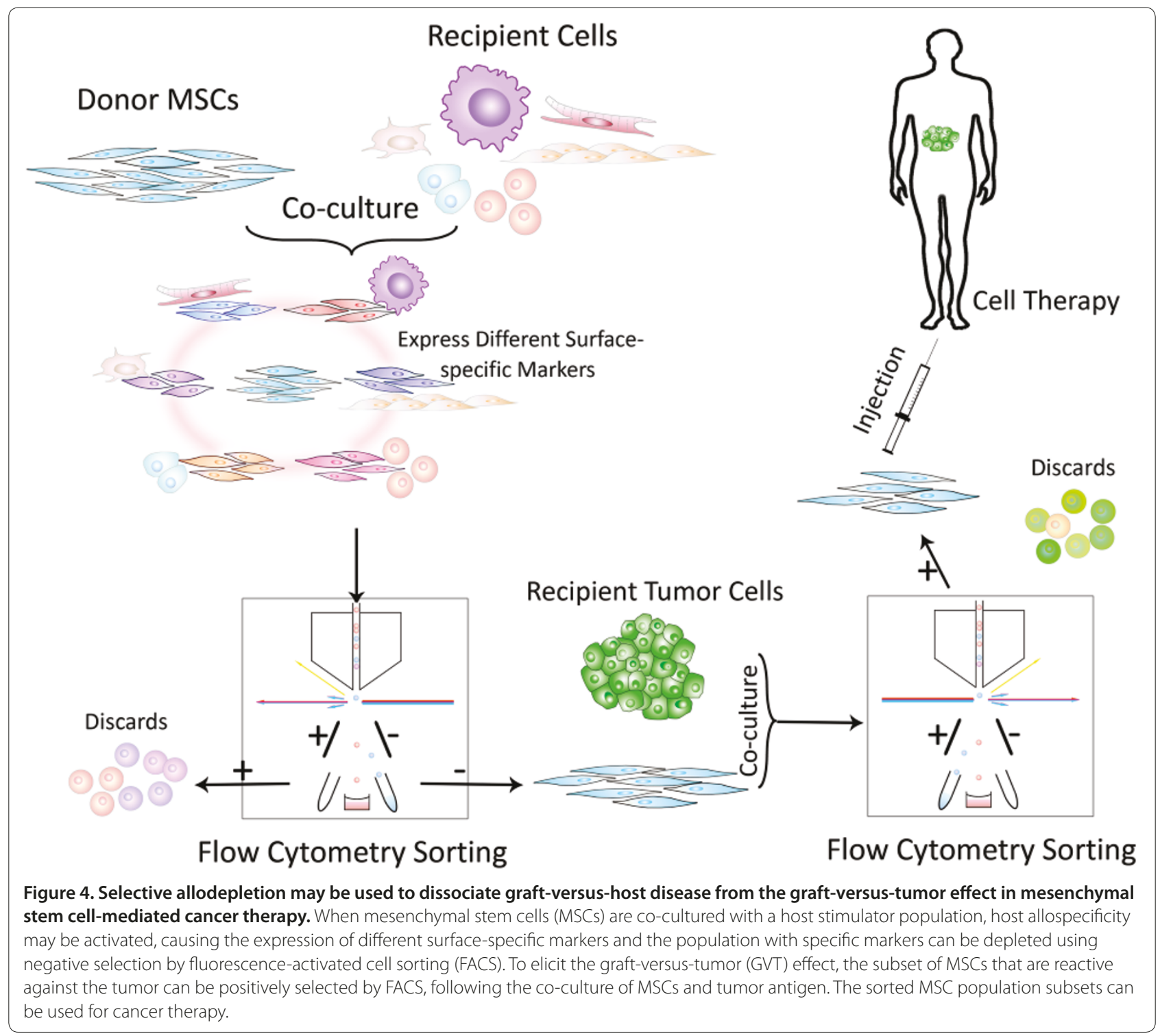

FACS. With regard to the heterogeneity of MSCs, it is possible that MSCs that are reactive against the host or the tumor will be present in the heterogeneous MSC population, which may result in the dissociation of GVHD from the GVT effect. The host-reactive MSCs can be eliminated by selective allodepletion. To elicit the GVT effect, the subset of MSCs with reactivity against the tumor can be positively selected by FACS following the co-culture of MSCs and tumor antigen (Figure 4).

\section{Conclusion}

MSCs have great potential for cancer therapy. They can be used as gene carriers for targeted cancer gene therapy, and unmodified MSCs demonstrate a marked capacity for inhibiting tumor progression in some cases. MSCs are a heterogeneous subset of stromal cells, and differences in their surface marker composition, differentiation ability and influence on immunoregulation establish this heterogeneity. They exhibit different characteristics in the tumor microenvironment. The phenotypic heterogeneity among MSCs may reflect their functional heterogeneity. Thus, the discrepancies among research results may be explained by the heterogeneity of MSCs. An important determinant that switches the tumor promoting and inhibiting roles of MSCs may be related to the immunoregulation of different subsets of MSCs. It will be important to balance GVHD and the GVT effect of MSCs when considering MSC-mediated cancer therapy. Selective allodepletion may be used to dissociate GVHD and the GVT effect before the advancement of MSC-mediated cancer gene therapy. 


\section{Abbreviations}

bFGF, basic fibroblast growth factor; FACS, fluorescence-activated cell sorting: FBS, fetal bovine serum; GVHD, graft-versus-host disease; GVT, graft-versustumor; IFN, interferon; IL, interleukin; MHC, major histocompatibility complex; MSC, mesenchymal stem cell; NK, natural killer; TAF, tumor-associated fibroblast.

\section{Competing interests}

There are no competing interests (political, personal, religious, ideological, academic, intellectual, commercial or any other) to declare in relation to this manuscript.

\section{Acknowledgements}

This work was supported by national natural science foundation, China (project number 81272255, 30971497, 91229122), Innovation subject foundation for doctoral student, Hunan province, China (project number CX2010B039), Hunan Natural Science Foundation (10JJ7003), National Training and Research Base for Talents of principles of carcinogenesis foundation (111 project: 111-2-12)

Published: 18 March 2013

\section{Reference}

1. Sun XY, Nong J, Qin K, Warnock GL, Dai LJ: Mesenchymal stem cell-mediated cancer therapy: A dual-targeted strategy of personalized medicine. World J Stem Cells 2011, 3:96-103.

2. Shah K: Mesenchymal stem cells engineered for cancer therapy. Adv Drug Deliv Rev 2011, 64:739-748.

3. Zachos T, Diggs A, Weisbrode S, Bartlett J, Bertone A: Mesenchymal stem cell-mediated gene delivery of bone morphogenetic protein-2 in an articular fracture model. Mol Ther 2007, 15:1543-1550.

4. Le Blanc K, Samuelsson H, Gustafsson B, Remberger M, Sundberg B, Arvidson $J$, Ljungman P, Lonnies H, Nava S, Ringden O: Transplantation of mesenchymal stem cells to enhance engraftment of hematopoietic stem cells. Leukemia 2007, 21:1733-1738.

5. Liu M, Han ZC: Mesenchymal stem cells: biology and clinical potential in type 1 diabetes therapy. J Cell Mol Med 2008, 12:1155-1168.

6. Zhang M, Mal N, Kiedrowski M, Chacko M, Askari AT, Popovic ZB, Koc ON, Penn MS: SDF-1 expression by mesenchymal stem cells results in trophic support of cardiac myocytes after myocardial infarction. FASEB J 2007, 21:3197-3207

7. Jurga M, Lipkowski AW, Lukomska B, Buzanska L, Kurzepa K, Sobanski T, Habich A, Coecke S, Gajkowska B, Domanska-Janik K: Generation of functional neural artificial tissue from human umbilical cord blood stem cells. Tissue Eng Part C Methods 2009, 15:365-372.

8. Nagaya N, Fujii T, Iwase T, Ohgushi H, Itoh T, Uematsu M, Yamagishi M, Mori H, Kangawa K, Kitamura S: Intravenous administration of mesenchymal stem cells improves cardiac function in rats with acute myocardial infarction through angiogenesis and myogenesis. Am J Physiol Heart Circ Physiol 2004, 287:H2670-2676.

9. Torsvik A, Rosland GV, Svendsen A, Molven A, Immervoll H, McCormack E, Lonning PE, Primon M, Sobala E, Tonn JC, Goldbrunner R, Schichor C, Mysliwietz J, Lah TT, Motaln H, Knappskog S, Bjerkvig R: Spontaneous malignant transformation of human mesenchymal stem cells reflects cross-contamination: putting the research field on track - letter. Cancer Res 2010, 70:6393-6396

10. Otsu K, Das S, Houser SD, Quadri SK, Bhattacharya S, Bhattacharya J: Concentration-dependent inhibition of angiogenesis by mesenchymal stem cells. Blood 2009, 113:4197-4205

11. Qiao L, Xu Z, Zhao T, Zhao Z, Shi M, Zhao RC, Ye L, Zhang X: Suppression of tumorigenesis by human mesenchymal stem cells in a hepatoma model. Cell Res 2008, 18:500-507.

12. Qiao L, Xu ZL, Zhao TJ, Ye LH, Zhang XD: Dkk-1 secreted by mesenchymal stem cells inhibits growth of breast cancer cells via depression of Wnt signalling. Cancer Lett 2008, 269:67-77.

13. Khakoo AY, Pati S, Anderson SA, Reid W, Elshal MF, Rovira, II, Nguyen AT, Malide D, Combs CA, Hall G, Zhang J, Raffeld M, Rogers TB, Stetler-Stevenson W, Frank JA, Reitz M, Finkel T: Human mesenchymal stem cells exert potent antitumorigenic effects in a model of Kaposi's sarcoma. J Exp Med 2006 203:1235-1247.

14. Klopp AH, Gupta A, Spaeth E, Andreeff M, Marini F, 3rd: Concise review:
Dissecting a discrepancy in the literature: do mesenchymal stem cells support or suppress tumor growth? Stem Cells 2011, 29:11-19.

15. Li L, Tian H, Chen Z, Yue W, Li S, Li W: Inhibition of lung cancer cell proliferation mediated by human mesenchymal stem cells. Acta Biochim Biophys Sin (Shanghai) 2011, 43:143-148.

16. Gauthaman K, Yee FC, Cheyyatraivendran S, Biswas A, Choolani M, Bongso A: Human umbilical cord Wharton's jelly stem cell (hWJSC) extracts inhibit cancer cell growth in vitro. J Cell Biochem 2012, 113:2027-2039.

17. Pisati F, Belicchi M, Acerbi F, Marchesi C, Giussani C, Gavina M, Javerzat S, Hagedorn M, Carrabba G, Lucini V, Gaini SM, Bresolin N, Bello L, Bikfalvi A Torrente Y: Effect of human skin-derived stem cells on vessel architecture, tumor growth, and tumor invasion in brain tumor animal models. Cancer Res 2007, 67:3054-3063

18. Bernardo ME, Zaffaroni N, Novara F, Cometa AM, Avanzini MA, Moretta A, Montagna D, Maccario R, Villa R, Daidone MG, Zuffardi O, Locatelli F: Human bone marrow derived mesenchymal stem cells do not undergo transformation after long-term in vitro culture and do not exhibit telomere maintenance mechanisms. Cancer Res 2007, 67:9142-9149.

19. Magee JA, Piskounova E, Morrison SJ: Cancer stem cells: impact, heterogeneity, and uncertainty. Cancer Cell 2012, 21:283-296.

20. Rosland GV, Svendsen A, Torsvik A, Sobala E, McCormack E, Immervoll H, Mysliwietz J, Tonn JC, Goldbrunner R, Lonning PE, Bjerkvig R, Schichor C: Long-term cultures of bone marrow-derived human mesenchymal stem cells frequently undergo spontaneous malignant transformation. Cancer Res 2009, 69:5331-5339.

21. Rubio D, Garcia-Castro J, Martin MC, de la Fuente R, Cigudosa JC, Lloyd AC, Bernad A: Spontaneous human adult stem cell transformation. Cancer Res 2005, 65:3035-3039.

22. Wang Y, Huso DL, Harrington J, Kellner J, Jeong DK, Turney J, McNiece IK. Outgrowth of a transformed cell population derived from normal human BM mesenchymal stem cell culture. Cytotherapy 2005, 7:509-519.

23. Shoshani O, Massalha H, Shani N, Kagan S, Ravid O, Madar S, Trakhtenbrot L, Leshkowitz D, Rechavi G, Zipori D: Polyploidization of murine mesenchymal cells is associated with suppression of the long non-coding RNA H19 and reduced tumorigenicity. Cancer Res 2012, 72:6403-6413.

24. Karnoub AE, Dash AB, Vo AP, Sullivan A, Brooks MW, Bell GW, Richardson AL, Polyak K, Tubo R, Weinberg RA: Mesenchymal stem cells within tumour stroma promote breast cancer metastasis. Nature 2007, 449:557-563.

25. Spaeth EL, Dembinski IL, Sasser AK, Watson K, Klopp A, Hall B, Andreeff M, Marini F: Mesenchymal stem cell transition to tumor-associated fibroblasts contributes to fibrovascular network expansion and tumor progression. PLoS One 2009, 4:e4992

26. Li HJ, Reinhardt F, Herschman HR, Weinberg RA: Cancer-stimulated mesenchymal stem cells create a carcinoma stem cell niche via prostaglandin E2 signaling. Cancer Discov 2012, 2:840-855.

27. Halpern JL, Kilbarger A, Lynch CC: Mesenchymal stem cells promote mammary cancer cell migration in vitro via the CXCR2 receptor. Cancer Lett 2011, 308:91-99.

28. Lis R, Touboul C, Raynaud CM, Malek JA, Suhre K, Mirshahi M, Rafii A: Mesenchymal cell interaction with ovarian cancer cells triggers prometastatic properties. PLoS One 2012, 7:e38340.

29. Zhao M, Sachs PC, Wang X, Dumur Cl, Idowu MO, Robila V, Francis MP, Ware J, Beckman M, Rizki A, Holt SE, Elmore LW: Mesenchymal stem cells in mammary adipose tissue stimulate progression of breast cancer resembling the basal-type. Cancer Biol Ther 2012, 13:782-792.

30. Reyes M, Dudek A, Jahagirdar B, Koodie L, Marker PH, Verfaillie CM: Origin of endothelial progenitors in human postnatal bone marrow. J Clin Invest 2002, 109:337-346

31. Oswald J, Boxberger S, Jorgensen B, Feldmann S, Ehninger G, Bornhauser M, Werner C: Mesenchymal stem cells can be differentiated into endothelial cells in vitro. Stem Cells 2004, 22:377-384

32. Dhar K, Dhar G, Majumder M, Haque I, Mehta S, Van Veldhuizen PJ, Banerjee SK, Banerjee S: Tumor cell-derived PDGF-B potentiates mouse mesenchymal stem cells-pericytes transition and recruitment through an interaction with NRP-1. Mol Cancer 2010, 9:209.

33. Ramasamy R, Lam EW, Soeiro I, Tisato V, Bonnet D, Dazzi F: Mesenchymal stem cells inhibit proliferation and apoptosis of tumor cells: impact on in vivo tumor growth. Leukemia 2007, 21:304-310.

34. Klopp AH, Lacerda L, Gupta A, Debeb BG, Solley T, Li L, Spaeth E, Xu W, Zhang X, Lewis MT, Reuben JM, Krishnamurthy S, Ferrari M, Gaspar R, BuchholzTA, Cristofanilli M, Marini F, Andreeff M, Woodward WA: Mesenchymal stem cells 
promote mammosphere formation and decrease E-cadherin in norma and malignant breast cells. PLoS One 2010, 5:e12180.

35. Chanda D, Kumar S, Ponnazhagan S: Therapeutic potential of adult bone marrow-derived mesenchymal stem cells in diseases of the skeleton. J Cell Biochem 2010, 111:249-257.

36. Kaplan RN, Riba RD, Zacharoulis S, Bramley AH, Vincent L, Costa C, MacDonald DD, Jin DK, Shido K, Kerns SA, Zhu Z, Hicklin D, Wu Y, Port JL, Altorki N, Port ER, Ruggero D, Shmelkov SV, Jensen KK, Rafii S, Lyden D: VEGFR1-positive haematopoietic bone marrow progenitors initiate the pre-metastatic niche. Nature 2005, 438:820-827.

37. Liu S, Ginestier C, Ou SJ, Clouthier SG, Patel SH, Monville F, Korkaya H, Heath A, Dutcher J, Kleer CG, Jung Y, Dontu G, Taichman R, Wicha MS: Breast cancer stem cells are regulated by mesenchymal stem cells through cytokine networks. Cancer Res 2011, 71:614-624.

38. Peinado H, Aleckovic M, Lavotshkin S, Matei I, Costa-Silva B, Moreno-Bueno G, Hergueta-Redondo M, Williams C, Garcia-Santos G, Ghajar C, NitadoriHoshino A, Hoffman C, Badal K, Garcia BA, Callahan MK, Yuan J, Martins VR, Skog J, Kaplan RN, Brady MS, Wolchok JD, Chapman PB, Kang Y, Bromberg J, Lyden D: Melanoma exosomes educate bone marrow progenitor cells toward a pro-metastatic phenotype through MET. Nat Med 2012, 18:883-891

39. Sceneay J, Chow MT, Chen A, Halse HM, Wong CS, Andrews DM, Sloan EK, Parker BS, Bowtell DD, Smyth MJ, Moller A: Primary tumor hypoxia recruits CD11b+/Ly6Cmed/Ly6G+ immune suppressor cells and compromises NK cell cytotoxicity in the premetastatic niche. Cancer Res 2012, 72:3906-3911.

40. Wels J, Kaplan RN, Rafii S, Lyden D: Migratory neighbors and distant invaders: tumor-associated niche cells. Genes Dev 2008, 22:559-574.

41. Paunescu V, Bojin FM, Tatu CA, Gavriliuc OI, Rosca A, Gruia AT, Tanasie G, Bunu C, Crisnic D, Gherghiceanu M, Tatu FR, Tatu CS, Vermesan S: Tumourassociated fibroblasts and mesenchymal stem cells: more similarities than differences. J Cell Mol Med 2011, 15:635-646.

42. Dawson MR, Chae SS, Jain RK, Duda DG: Direct evidence for lineagedependent effects of bone marrow stromal cells on tumor progression. Am J Cancer Res 2011, 1:144-154.

43. Zhang L, Tang A, Zhou Y, Tang J, Luo Z, Jiang C, Li X, Xiang J, Li G: Tumorconditioned mesenchymal stem cells display hematopoietic differentiation and diminished influx of ca(2+). Stem Cells Dev 2012, 21:1418-1428

44. Peiffer I, Eid P, Barbet R, Li ML, Oostendorp RA, Haydont V, Monier MN, Milon L, Fortunel N, Charbord P, Tovey M, Hatzfeld J, Hatzfeld A: A sub-population of high proliferative potential-quiescent human mesenchymal stem cells is under the reversible control of interferon alpha/beta. Leukemia 2007 21:714-724.

45. Martinez-Lorenzo MJ, Royo-Canas M, Alegre-Aguaron E, Desportes P, Castiella T, Garcia-Alvarez F, Larrad L: Phenotype and chondrogenic differentiation of mesenchymal cells from adipose tissue of different species. J Orthop Res 2009, 27:1499-1507.

46. Arufe MC, De la Fuente A, Fuentes-Boquete I, De Toro FJ, Blanco FJ: Differentiation of synovial CD-105(+) human mesenchymal stem cells into chondrocyte-like cells through spheroid formation. J Cell Biochem 2009, 108:145-155.

47. Liu H, Toh WS, Lu K, MacAry PA, Kemeny DM, Cao T: A subpopulation of mesenchymal stromal cells with high osteogenic potential. $J$ Cell Mol Med 2009, 13:2436-2447

48. Tondreau T, Meuleman N, Delforge A, Dejeneffe M, Leroy R, Massy M, Mortier C, Bron D, Lagneaux L: Mesenchymal stem cells derived from CD133positive cells in mobilized peripheral blood and cord blood: proliferation, Oct4 expression, and plasticity. Stem Cells 2005, 23:1105-1112.

49. Pozzobon M, Piccoli M, Ditadi A, Bollini S, Destro R, Andre-Schmutz I, Masiero L, Lenzini E, Zanesco L, Petrelli L, Cavazzana-Calvo M, Gazzola MV, De Coppi P: Mesenchymal stromal cells can be derived from bone marrow CD133+ cells: implications for therapy. Stem Cells Dev 2009, 18:497-510.

50. Wei F, Wang T, Liu J, Du Y, Ma A: The subpopulation of mesenchymal stem cells that differentiate toward cardiomyocytes is cardiac progenitor cells. Exp Cell Res 2011, 317:2661-2670.

51. Bolontrade MF, Sganga L, Piaggio E, Viale DL, Sorrentino MA, Robinson A, Sevlever G, Garcia MG, Mazzolini G, Podhajcer OL: A specific subpopulation of mesenchymal stromal cell carriers overrides melanoma resistance to an oncolytic adenovirus. Stem Cells Dev 2012, 21:2689-2702.

52. Pittenger MF, Martin BJ: Mesenchymal stem cells and their potential as cardiac therapeutics. Circ Res 2004, 95:9-20.
53. Salehinejad P, Alitheen NB, Ali AM, Omar AR, Mohit M, Janzamin E, Samani FS, Torshizi Z, Nematollahi-Mahani SN: Comparison of different methods for the isolation of mesenchymal stem cells from human umbilical cord Wharton's jelly. In Vitro Cell Dev Biol Anim 2012, 48:75-83.

54. Alegre-Aguarón E: Differences in surface marker expression and chondrogenic potential among various tissue-derived mesenchymal cells from elderly patients with osteoarthritis. Cells Tissues Organs 2012, 196:231-240.

55. Chase LG, Lakshmipathy U, Solchaga LA, Rao MS, Vemuri MC: A novel serumfree medium for the expansion of human mesenchymal stem cells. Stem Cell Res Ther 2010, 1:8.

56. Li YM, Schilling T, Benisch P, Zeck S, Meissner-Weigl J, Schneider D, Limbert C, Seufert J, Kassem M, Schutze N, Jakob F, Ebert R: Effects of high glucose on mesenchymal stem cell proliferation and differentiation. Biochem Biophys Res Commun 2007, 363:209-215.

57. Szade K, Zuba-Surma E, Rutkowski AJ, Jozkowicz A, Dulak J: CD45-CD14 + CD34 + murine bone marrow low-adherent mesenchymal primitive cells preserve multilineage differentiation potential in long-term in vitro culture. Mol Cells 2011, 31:497-507.

58. Spitzer TL, Rojas A, Zelenko Z, Aghajanova L, Erikson DW, Barragan F, Meyer M, Tamaresis JS, Hamilton AE, Irwin JC, Giudice LC: Perivascular human endometrial mesenchymal stem cells express pathways relevant to selfrenewal, lineage specification, and functional phenotype. Biol Reprod 2012, 86:58.

59. Patel SA, Sherman L, Munoz J, Rameshwar P: Immunological properties of mesenchymal stem cells and clinical implications. Arch Immunol Ther Exp (Warsz) 2008, 56:1-8.

60. Prevosto C, Zancolli M, Canevali P, Zocchi MR, Poggi A: Generation of CD4+ or CD8+ regulatory T cells upon mesenchymal stem cell-lymphocyte interaction. Haematologica 2007, 92:881-888.

61. Bassi EJ, de Almeida DC, Moraes-Vieira PM, Camara NO: Exploring the role of soluble factors associated with immune regulatory properties of mesenchymal stem cells. Stem Cell Rev 2012, 8:329-342.

62. Lin CS, Lin G, Lue TF: Allogeneic and xenogeneic transplantation of adipose-derived stem cells in immunocompetent recipients without immunosuppressants. Stem Cells Dev 2012, 21:2770-2778.

63. Xiang J, Tang J, Song C, Yang Z, Hirst DG, Zheng QJ, Li G: Mesenchymal stem cells as a gene therapy carrier for treatment of fibrosarcoma. Cytotherapy 2009, 11:516-526.

64. Hao L, Sun H, Wang J, Wang T, Wang M, Zou Z: Mesenchymal stromal cells for cell therapy: besides supporting hematopoiesis. Int J Hematol 2011, 95:34-46.

65. Chan JL, Tang KC, Patel AP, Bonilla LM, Pierobon N, Ponzio NM, Rameshwar P: Antigen-presenting property of mesenchymal stem cells occurs during a narrow window at low levels of interferon-gamma. Blood 2006, 107:4817-4824.

66. Chen X, McClurg A, Zhou GQ, McCaigue M, Armstrong MA, Li G: Chondrogenic differentiation alters the immunosuppressive property of bone marrow-derived mesenchymal stem cells, and the effect is partially due to the upregulated expression of B7 molecules. Stem Cells 2007, 25:364-370.

67. Zhao ZG, Li WM, Chen ZC, You Y, Zou P: Hematopoiesis capacity, immunomodulatory effect and ex vivo expansion potential of mesenchymal stem cells are not impaired by cryopreservation. Cancer Invest 2008, 26:391-400.

68. Xishan Z, Guangyu A, Yuguang S, Hongmei Z: The research on the immunomodulatory defect of mesenchymal stem cell from chronic myeloid leukemia patients. J Exp Clin Cancer Res 2011, 30:47.

69. Arnulf B, Lecourt S, Soulier J, Ternaux B, Lacassagne MN, Crinquette A, Dessoly J, Sciaini AK, Benbunan M, Chomienne C, Fermand JP, Marolleau JP, Larghero $\mathrm{J}$ : Phenotypic and functional characterization of bone marrow mesenchymal stem cells derived from patients with multiple myeloma. Leukemia 2007, 21:158-163.

70. Perez-Simon JA, Tabera S, Sarasquete ME, Diez-Campelo M, Canchado J, Sanchez-Abarca LI, Blanco B, Alberca I, Herrero-Sanchez C, Canizo C, San Miguel JF: Mesenchymal stem cells are functionally abnormal in patients with immune thrombocytopenic purpura. Cytotherapy 2009, 11:698-705.

71. Djouad F, Fritz V, Apparailly F, Louis-Plence P, Bony C, Sany J, Jorgensen C, Noel $D$ : Reversal of the immunosuppressive properties of mesenchymal stem cells by tumor necrosis factor alpha in collagen-induced arthritis. Arthritis Rheum 2005, 52:1595-1603. 
72. Buravkova LB, Grigorieva OG, Andreeva ER, Andrianova IV, Rylova YV: Subpopulation composition and activation of T lymphocytes during coculturing with mesenchymal stromal cells in medium with different O(2) content. Bull Exp Biol Med 2011, 151:344-346.

73. Nasef A, Zhang YZ, Mazurier C, Bouchet S, Bensidhoum M, Francois S, Gorin NC, Lopez M, Thierry D, Fouillard L, Chapel A: Selected Stro-1-enriched bone marrow stromal cells display a major suppressive effect on lymphocyte proliferation. Int J Lab Hematol 2009, 31:9-19.

74. Francois M, Romieu-Mourez R, Stock-Martineau S, Boivin MN, Bramson JL, Galipeau J: Mesenchymal stromal cells cross-present soluble exogenous antigens as part of their antigen-presenting cell properties. Blood 2009, 114:2632-2638

75. Remberger M, Kumlien G, Aschan J, Barkholt L, Hentschke $P$, Ljungman $P$, Mattsson J, Svennilson J, Ringden O: Risk factors for moderate-to-severe chronic graft-versus-host disease after allogeneic hematopoietic stem cell transplantation. Biol Blood Marrow Transplant 2002, 8:674-682.

76. Baron F, Maris MB, Sandmaier BM, Storer BE, Sorror M, Diaconescu R, Woolfrey AE, Chauncey TR, Flowers ME, Mielcarek M, Maloney DG, Storb R: Graftversus-tumor effects after allogeneic hematopoietic cell transplantation with nonmyeloablative conditioning. J Clin Oncol 2005, 23:1993-2003.

77. Rassa JC, Meyers JL, Zhang Y, Kudaravalli R, Ross SR: Murine retroviruses activate B cells via interaction with toll-like receptor 4. Proc Natl Acad SC US A 2002, 99:2281-2286

78. Klyushnenkova E, Mosca JD, Zernetkina V, Majumdar MK, Beggs KJ, Simonetti DW, Deans RJ, McIntosh KR: T cell responses to allogeneic human mesenchymal stem cells: immunogenicity, tolerance, and suppression. J Biomed Sci 2005, 12:47-57.

79. Radoja S, Rao TD, Hillman D, Frey AB: Mice bearing late-stage tumors have normal functional systemic T cell responses in vitro and in vivo. $\mathrm{J} / \mathrm{mmuno}$ 2000, 164:2619-2628.

80. Hammarstrom L, Smith Cl: T-cell functions in nude mice: proliferation of spleen cells from athymic mice in the one-way xenogeneic mixed leucocyte reaction. Scand I Immunol 1980, 12:213-221.

81. Petrini I, Pacini S, Petrini M, Fazzi R, Trombi L, Galimberti S: Mesenchymal cells inhibit expansion but not cytotoxicity exerted by gamma-delta T cells. Eur J Clin Invest 2009, 39:813-818.
82. Lavergne E, Combadiere B, Bonduelle O, Iga M, Gao JL, Maho M, Boissonnas A, Murphy PM, Debre P, Combadiere C: Fractalkine mediates natural killerdependent antitumor responses in vivo. Cancer Res 2003, 63:7468-7474.

83. Nagahara K, Arikawa T, Oomizu S, Kontani K, Nobumoto A, Tateno H, Watanabe K, Niki T, Katoh S, Miyake M, Nagahata S, Hirabayashi J, Kuchroo VK, Yamauchi A, Hirashima M: Galectin-9 increases Tim-3+ dendritic cells and CD8+ T cells and enhances antitumor immunity via galectin-9-Tim-3 interactions. J Immuno/ 2008, 181:7660-7669.

84. Wang HF, Shi YJ, Ren HY: [Bone Marrow-derived Mesenchymal Stem Cells Regulate the Proliferation and Activity of Natural Killer Cells]. Zhongguo Shi Yan Xue Ye Xue Za Zhi 2012, 20:438-442.

85. Abe T, Kawamura H, Kawabe S, Watanabe H, Gejyo F, Abo T: Liver injury due to sequential activation of natural killer cells and natural killer T cells by carrageenan. J Hepatol 2002, 36:614-623.

86. Carson WE, Yu H, Dierksheide J, Pfeffer K, Bouchard P, Clark R, Durbin J, Baldwin AS, Peschon J, Johnson PR, Ku G, Baumann H, Caligiuri MA: A fatal cytokine-induced systemic inflammatory response reveals a critical role for NK cells. J Immunol 1999, 162:4943-4951.

87. Gannage M, Buzyn A, Bogiatzi SI, Lambert M, Soumelis V, Dal Cortivo L, Cavazzana-Calvo M, Brousse N, Caillat-Zucman S: Induction of NKG2D ligands by gamma radiation and tumor necrosis factor-alpha may participate in the tissue damage during acute graft-versus-host disease. Transplantation 2008, 85:911-915.

88. Tsirigotis P, Or R, Resnick IB, Shapira MY: Immunotherapeutic approaches to improve graft-versus-tumor effect and reduce graft-versus-host disease. Immunotherapy 2012, 4:407-424.

doi:10.1186/scrt170

Cite this article as: Zhang $L$, et al:: The uncertain role of unmodified mesenchymal stem cells in tumor progression: what master switch? Stem Cell Research \& Therapy 2013, 4:22 